\title{
Thermal Insulation from Construction Coating Mixed with Porous Calcium-containing Solid Waste
}

\author{
Hsi-Chi Yang and Tsung-Pin Tsai
}

\begin{abstract}
To resolve the health risk from the exposure of calcium hydroxide, the target of the present work is to stabilize the solid waste and reuse it as green material for construction buildings. An efficient chemical-wet method is adopted to synthesize $\mathrm{CaSO}_{4}$ and $\mathrm{CaSO}_{4} \cdot 2 \mathrm{H}_{2} \mathrm{O}$ powders from $\mathrm{Ca}(\mathrm{OH})_{2}$ waste in the presence of diluted sulfuric acid at ambient temperature. The improved thermal insulation from the construction coating mixed with porous $\mathrm{CaSO}_{4}$ powders has been investigated. The as-prepared $\mathrm{CaSO}_{4}$ powders are stable in atmospheric pressure and easily stored as solid waste without toxicity. The construction coating mixed with porous $\mathrm{CaSO}_{4}$ powders offers excellent thermal insulation capability, as compared with pristine one. The enhanced performance can be attributed to the fact that the $\mathrm{CaSO}_{4}$ powders possess a vast porous framework, allowing a large amount of air trapped in the construction coating against the thermal transfer. Since the $\mathrm{CaSO}_{4}$ powders is efficiently prepared from toxic solid waste, the chemical-wet method exhibits a potential route to produce green construction materials for various applications due to its simplicity, high recycling ratio, non-toxicity, low cost, and environmental friendliness.
\end{abstract}

Index Terms-Thermal insulation, calcium sulfate powders, solid waste, construction coating.

\section{INTRODUCTION}

Calcium hydroxide, conventionally called slaked lime, is an inorganic compound with the chemical formula $\mathrm{Ca}(\mathrm{OH})_{2}$. Calcium hydroxide is also called hydrated lime, caustic lime, slack lime, and pickling lime. It is a colorless crystal or white powder and is obtained when calcium oxide (called lime or quicklime) is well mixed. Calcium hydroxide is used in many applications, including food preparation and flue-gas desulfurization. Limewater is the common name for a saturated solution of calcium hydroxide. Since $\mathrm{Ca}(\mathrm{OH})_{2}$ possesses a high solubility in water (i.e., limewater), it should be seriously limited because of skin irritation, chemical burning, blindness or lung damage to human kind.

To resolve the health risk from the exposure of calcium hydroxide, the target of the present work is to stabilize the solid waste and reuse it as green material for construction buildings. This work aims at the development of recycling process for reuse of calcium hydroxide. It is well known that $\mathrm{CaSO}_{4}$ material is one of the most promising construction materials for inner decoration due to its non-toxicity, low cost, and good environmental friendliness. Several approaches have been explored to synthesize calcium sulfate materials,

Manuscript received March 20, 2017; revised June 15, 2017.

Hsi-Chi Yang is with the Chung Hua University, China (e-mail: hcyangse@chu.edu.tw). using hydrothermal reaction [1], reactive crystallization [2][4], chemical extraction using organic media [5], and calcination-acidification [6]. Our strategy is to chemically transfer $\mathrm{Ca}(\mathrm{OH})_{2}$ to $\mathrm{CaSO}_{4}$ in the presence of diluted sulfuric acid. The as-prepared $\mathrm{CaSO}_{4}$ powders can be mixed water-soluble paint and then coated over calcium silicate plates, offering better thermal and fire resistances as compared with the original one. Since the $\mathrm{CaSO}_{4}$ powders could be prepared from industrial solid waste, the chemical method opens a straightforward pathway to produce green construction materials, showing superior thermal resistance.

\section{EXPERIMENTAL SECTION}

The solid waste was collected from a food-processing factory (Taoyuan, Taiwan). The solid waste, consisted of $\mathrm{Ca}(\mathrm{OH})_{2}$ and $\mathrm{CaSO}_{4}$ (i.e., $\mathrm{Ca}(\mathrm{OH})_{2}: \mathrm{CaSO}_{4}=8: 2$ in w/w), was grounded into several micrometers by using ball mill. Afterward, the solid waste was slowly added into $1 \mathrm{M} \mathrm{H}_{2} \mathrm{SO}_{4}$ solution. The chemical process was carried out at ambient temperature for $1 \mathrm{~h}$, allowing the formation of $\mathrm{CaSO}_{4}$ or $\mathrm{CaSO}_{4} \cdot 2 \mathrm{H}_{2} \mathrm{O}$ with high chemical conversion. Finally, white powders were precipitated in the bottom of beaker and were dried at $105^{\circ} \mathrm{C}$ in an oven overnight.

Field-emission scanning electron microscopy (FE-SEM; JEOL JSM-5600) was adopted to observe the microstructural morphology of as-prepared $\mathrm{CaSO}_{4}$ powders. To examine the thermal resistance, water-soluble painting mixed with $\mathrm{CaSO}_{4}$ powders were prepared to coat over calcium silicate plates. The calcium silicate plate was carefully cut into an area of $5 \times$ $5 \mathrm{~cm}^{2}$, and its thickness was $0.5 \mathrm{~cm}$. Three painting samples were prepared with 0,5 and $10 \mathrm{wt} \%$ of $\mathrm{CaSO}_{4}$ powders in water-soluble paints, which were designated to CC-1, CC-2, and CC-3, respectively. For uniformity, the paintings were first blended with a three-dimensional mixer using zirconia balls for $10 \mathrm{~min}$. The as-prepared paintings were pasted on the substrates with a doctor blade and then dried at $80^{\circ} \mathrm{C}$ in an oven overnight. Nitrogen physisorption technique has been employed to analyze the surface characteristics of $\mathrm{CaSO}_{4}$ powders. An automated adsorption apparatus (Micromeritics, ASAP 2020) was adopted to characterize the porous nature of $\mathrm{CaSO}_{4}$ powders, using $\mathrm{N}_{2}$ physisorption at $-196^{\circ} \mathrm{C}$. Nitrogen surface areas of the samples were determined from Brunauer-Emmett-Teller (BET) equation.

An experiment regarding thermal resistances on as-prepared paintings could be briefly described as follows. The $\mathrm{CaSO}_{4}$-containing paints were tightly adhered to one hot plate by using a securing clip. The surface temperature of the hot plate was kept at $100^{\circ} \mathrm{C}$. One thermal imaging apparatus was used to observe temperature distribution on each sample, 
meanwhile three thermocouples ( $K$ type) were used to detect surface temperatures of the painting. The surface temperatures were stabilized after the test period of $20 \mathrm{~min}$.

\section{RESUlTS AND DisCUSSION}

Figs. 1(a) and 1(b) show top-view FE-SEM image of as-prepared $\mathrm{CaSO}_{4}$ powders with low and high magnification, respectively. The photos reveal that the as-prepared powders have highly roughened surface. The average particle size of $\mathrm{CaSO}_{4}$ powders ranges from 1 to $5 \mu \mathrm{m}$, indicating homogeneous distribution of particle size. Two reaction steps in the presence of sulfuric acid can be formulated as follows:

$$
\begin{gathered}
\mathrm{Ca}(\mathrm{OH})_{2}+\mathrm{H}_{2} \mathrm{SO}_{4}=\mathrm{CaSO}_{4}+2 \mathrm{H}_{2} \mathrm{O} \\
\mathrm{Ca}^{2+}+\mathrm{SO}_{4}{ }^{2-}+2 \mathrm{H}_{2} \mathrm{O}=\mathrm{CaSO}_{4} \cdot 2 \mathrm{H}_{2} \mathrm{O}
\end{gathered}
$$

Basically, the chemical route is capable of producing calcium sulfate (Eq. (1)) or di-hydrated calcium sulfate (Eq. (2)) powders, which are stable at ambient temperature in air (its melting temperature: $1460^{\circ} \mathrm{C}$ ) and can be stored as solid waste without toxicity. Thus, the chemical-wet method shows a scalable feasibility for producing green architecture materials due to its simplicity, high efficiency, and easy operation. To examine its practical applicability for thermal insulation, the porous characteristics of as-prepared $\mathrm{CaSO}_{4}$ powder is further analyzed by physical adsorption of nitrogen. The BET surface area and total pore volume of $\mathrm{CaSO}_{4}$ powders are $102 \mathrm{~m}^{2} / \mathrm{g}$ and $0.23 \mathrm{~cm}^{3} / \mathrm{g}$, respectively. The finding reflects that the $\mathrm{CaSO}_{4}$ powders are porous, allowing a large amount of air trapped in the porous structure.
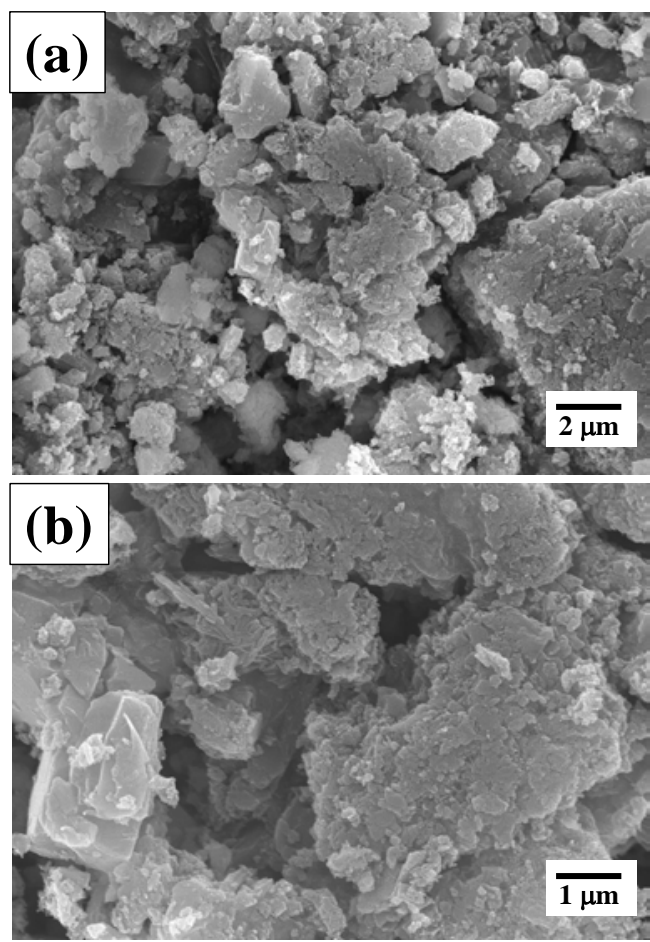

Fig. 1. Top-view FE-SEM photograph of as-prepared $\mathrm{CaSO}_{4} \cdot$ powders.

Thermal imaging photographs for pristine (i.e., CC-1) and $\mathrm{CaSO}_{4}$-containing painting (i.e., CC-3) on the substrates, placed on the hot plate with a stable temperature of approximately $100^{\circ} \mathrm{C}$, are illustrated in Fig. 2. It can be observed that the surface temperature of CC-1 sample displays a rapid increase as an increase in time. After $10 \mathrm{~min}$, the temperature of CC-1 sample reaches to approximately $100^{\circ} \mathrm{C}$, which is very close to the hot plate. In contrast, the CC-3 sample offers an improved thermal insulation capability, as compared to the CC-1 one. After $10 \mathrm{~min}$, the surface temperature of CC-3 sample only reaches to $\sim 80^{\circ} \mathrm{C}$, revealing a strong resistance of thermal conduction in the CC-3 coating.

TABLE I: POROUS STRUCTURES OF CONSTRUCTION MATERIALS DETERMINED FROM NITROGEN PHYSISORPTION AT $-196^{\circ} \mathrm{C}$

\begin{tabular}{ccc}
\multicolumn{2}{c}{ DETERMINED FROM NITROGEN PHYSISORPTION AT $-196^{\circ} \mathrm{C}}$. \\
$\begin{array}{c}\text { Sample } \\
\text { type }\end{array}$ & $\begin{array}{c}S_{\mathrm{BET}}{ }^{a} \\
\left(\frac{\left.\mathrm{m}^{2} / \mathrm{g}\right)}{}\right.\end{array}$ & $\begin{array}{c}V_{\mathrm{t}}{ }^{b} \\
\left(\mathrm{~cm}^{3} / \mathrm{g}\right) .\end{array}$ \\
CC-1 & 10.1 & 0.11 \\
CC-2 & 14.7 & 0.12 \\
CC-3 & 20.6 & 0.14 \\
\hline${ }^{a}$ & $S_{\mathrm{BET}}:$ Specific surface area computed using the BET equation. \\
${ }^{b}$ & $V_{\mathrm{t}}:$ Total pore volume estimated at a relative pressure of 0.98.
\end{tabular}

To inspect the thermal property, the effect of $\mathrm{CaSO}_{4}$ content on the surface temperature of painting is investigated. Fig. 3 evidently indicates that the surface temperature is an increasing function of heating time for all construction coatings. After $20 \mathrm{~min}$, all construction coatings maintain a stable temperature difference between the hot plate and the $\mathrm{CaSO}_{4}$-containing coating. As shown in Fig. 4, the CC-3 coating exhibits the lowest ramping rate (i.e., $5.6{ }^{\circ} \mathrm{C} / \mathrm{min}$ within the first ten minutes) and the highest stable temperature difference (i.e., $\sim 6^{\circ} \mathrm{C}$ ), as compared to the others. As a result, the introduction of $\mathrm{CaSO}_{4}$ powders is able to provide a thermal barrier, hindering the heat transfer from heat source (i.e., a hot plate used in this case). It is recognized that thermal conductivity of air is approximately $0.026 \mathrm{~W} / \mathrm{m}$ $\mathrm{K}$ [7]. The thermal conductivity of standard gypsum matrix is $\sim 0.60 \mathrm{~W} / \mathrm{m} \mathrm{K}$ [8], 23 times higher that of air. To support the above argument, Table I shows the porous characteristics of different construction paintings, determined from the data of $\mathrm{N}_{2}$ adsorption isotherms. It is found that pristine CC-1 sample displays a BET surface area of $10.1 \mathrm{~m}^{2} \mathrm{~g}^{-1}$, much lower than CC-2 and CC-3 samples. Similarly, the total pore volume of the patintings also delivers the same trend. Accordingly, both the BET surface area and total pore volume are increasing fucntions of the amount of $\mathrm{CaSO}_{4}$ powders. Thus, the addition of $\mathrm{CaSO}_{4}$ powders into the painting is capable of raising the porosity, providing the thermal resistive layer.

It is known that gypsum $\left(\mathrm{CaSO}_{4} \cdot 2 \mathrm{H}_{2} \mathrm{O}\right)$ could serve as a retarder for fireproof construction coatings [9], [10]. Thus, the introduction of $\mathrm{CaSO}_{4} \cdot 2 \mathrm{H}_{2} \mathrm{O}$ powders is beneficial for improving the thermal transfer through the composite paintings. This deduction mainly originates from the fact that the thermal decomposition of $\mathrm{CaSO}_{4} \cdot 2 \mathrm{H}_{2} \mathrm{O}$ powders is an endothermic reaction, allowing the heat absorption in the gypsum content. When heating the gypsum-contained painting, the overall reaction steps could be formulated as follows:

$$
\begin{gathered}
\mathrm{CaSO}_{4} \cdot 2 \mathrm{H}_{2} \mathrm{O}(\mathrm{di})=\mathrm{CaSO}_{4} \cdot 1 / 2 \mathrm{H}_{2} \mathrm{O}+3 / 2 \mathrm{H}_{2} \mathrm{O} \\
\mathrm{CaSO}_{4} \cdot 1 / 2 \mathrm{H}_{2} \mathrm{O}(\beta)=\mathrm{CaSO}_{4}+1 / 2 \mathrm{H}_{2} \mathrm{O}
\end{gathered}
$$

The first step can be assigned to the departure of $3 / 2 \mathrm{~mol}$ $\mathrm{H}_{2} \mathrm{O}$ from dihydrated calcium sulfate, whereas the second 
one is related to the departure of $1 / 2 \mathrm{~mol}_{2} \mathrm{O}$ from hemihydrated calcium sulfate obtained after the incomplete dehydration of dihydrated calcium sulfate and from the $\beta$-hemihydrate of plaster (i.e., a phase transformation) [10], [11]. Since both the reaction steps are endothermic, the heat transfer through the gypsum-containing composite painting would be alleviated until the endothermic steps are totally completed [12]. Therefore, the gypsum-containing painting offers a trailing effect, inducing excellent thermal resistance. On the basis of experimental results, the enhanced thermal-insulating performance originates from the fact that the addition of $\mathrm{CaSO}_{4}$ powders creates a porous framework in the construction coating, inducing an air pocket against heat transfer.

(a)

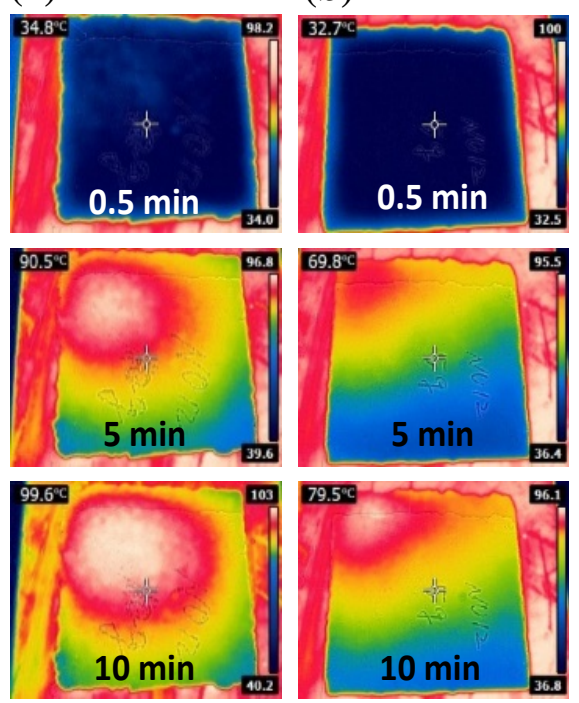

Fig. 2. Thermal imaging photographs of the painting mixed with (a) 0 and (b) $10 \mathrm{wt} \% \mathrm{CaSO}_{4}$ powders on the substrates. The surface temperature of hot plate was set at $100^{\circ} \mathrm{C}$.

On the basis of experimental results, the addition of $\mathrm{CaSO}_{4}$ powders significantly increases the amount of air layer against the thermal conduction due to its vast pore structure. Accordingly, the stacking of $\mathrm{CaSO}_{4}$ powders contains a large amount of air that gives high-quality thermal insulation. The magnitude of thermal conductivity on the composite coating strongly decreases with an increase of fraction of porosity [13]. Accordingly, the larger amount of $\mathrm{CaSO}_{4}$ powders in the construction coating, the better thermal-insulating performance can attain, due to an air layer trapped in the porous $\mathrm{CaSO}_{4}$ powders.

To further investigate the practical applicability, one set of experiment regarding the cycleability was performed to identify the thermal insulation performance. Each sample (i.e., CC-1, CC-2, and CC-3 coating) was initially heated to $100^{\circ} \mathrm{C}$ and then maintained at this temperature for $30 \mathrm{~min}$. The heating rate within $10 \mathrm{~min}$ and stable temperature difference were accurately recorded and collected. The variation of heating rate and stable temperature difference with the cycle number is illustrated in Fig. 5. It can be seen that all construction coatings display very stable thermal-insulating ability. As expected, the CC-3 coating shows the best thermal-insulation performance among the construction samples. After 10 cycles, the lowest heating rate and the largest temperature difference of CC-3 coating can reach to $5.6{ }^{\circ} \mathrm{C} / \mathrm{min}$ and $6.2^{\circ} \mathrm{C}$, respectively. Thus, the composite coating serves as excellent thermal barrier in a variety of construction applications, especially for green building materials.

Since the as-prepared $\mathrm{CaSO}_{4}$ powders are free of charge, the prime cost of $\mathrm{CaSO}_{4}$ powders mainly depends on the amount of dilute sulfuric acid. The cost of hydrated $\mathrm{CaSO}_{4}$ powders by the as-proposed method is thus estimated to be approximately 0.18 US dollar $/ \mathrm{kg}$, based on the $100 \%$ conversion (i.e., the chemical reaction (R1): $\mathrm{Ca}(\mathrm{OH})_{2}+$ $\mathrm{H}_{2} \mathrm{SO}_{4}=\mathrm{CaSO}_{4}+2 \mathrm{H}_{2} \mathrm{O}$ ) and the usage of industrial-grade reagents. The unit price of home-made $\mathrm{CaSO}_{4}$ powders is much less than that of commercial products (i.e., 2-10 US dollar $/ \mathrm{kg}$ ). Thus, the simple chemical-wet synthesis of $\mathrm{CaSO}_{4}$ powders from waste solid offers a promising feasibility for commercialization due to its low cost and eco-friendless.

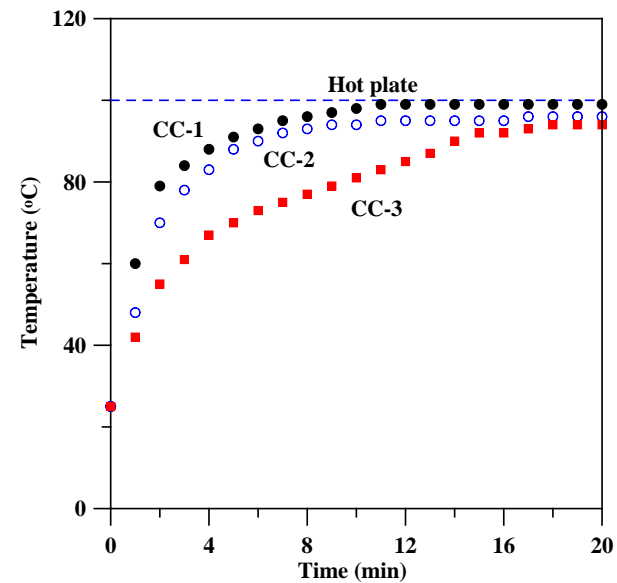

Fig. 3. The surface temperature of the $\mathrm{CaSO}_{4}$-containing painting as a function of heating period.

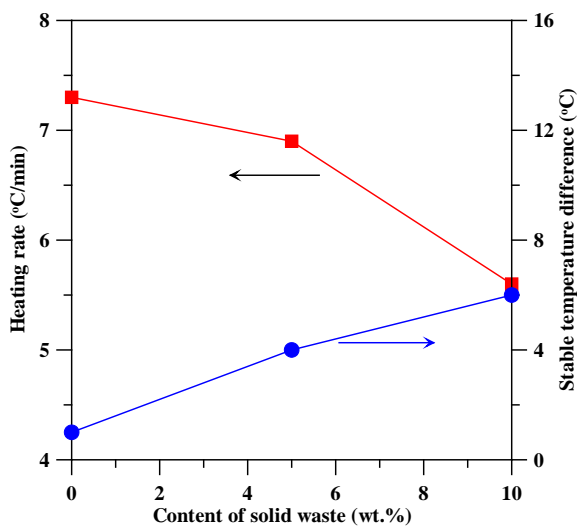

Fig. 4. The heating rate and stable temperature difference as a function of $\mathrm{CaSO}_{4}$ content.

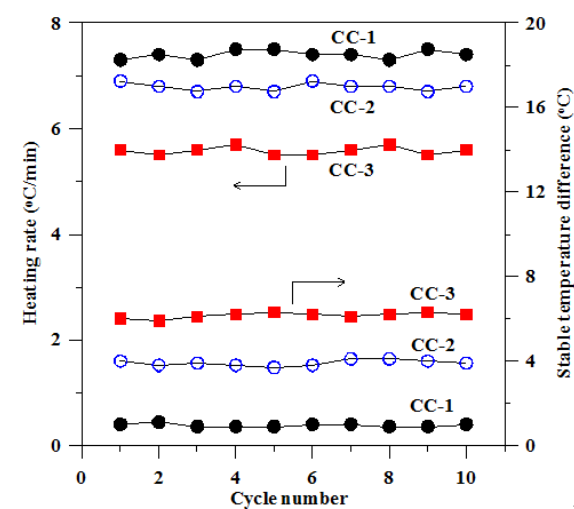

Fig. 5. The heating rate and stable temperature difference as a function of cycle number. 


\section{CONCLUSION}

We have presented an improved thermal resistance from the construction coating mixed with $\mathrm{CaSO}_{4}$ powders, prepared from the chemical-wet approach using toxic $\mathrm{Ca}(\mathrm{OH})_{2}$ waste as precursor. The efficient chemical-wet approach was prone to produce $\mathrm{CaSO}_{4}$ and $\mathrm{CaSO}_{4} \cdot 2 \mathrm{H}_{2} \mathrm{O}$ powders, which could be stable in air and easily stored as solid waste. The low heating rate and high stable temperature difference revealed that the addition of $\mathrm{CaSO}_{4}$ powders offers a strong thermal barrier against the thermal transfer from heat source. Since the $\mathrm{CaSO}_{4}$ powders were prepared from industrial solid waste, the simple chemical-wet method delivered a potential pathway to produce green construction materials for various applications owing to its simplicity, high recycling ratio, non-toxicity, low cost, and environmental friendliness.

\section{ACKNOWLEDGEMENT}

The authors are very grateful for the financial support from the Ministry of Science and Technology (Taiwan) under the contract NSC 101-2221-E-216-031-040.

\section{REFERENCES}

[1] S. C. Hou and L. Xiang, "Influence of activity of $\mathrm{CaSO}_{4} \cdot 2 \mathrm{H}_{2} \mathrm{O}$ on hydrothermal formation of $\mathrm{CaSO}_{4} \cdot 0.5 \mathrm{H}_{2} \mathrm{O}$ whiskers," J. Nanomater., pp. 1-5, March 2013.

[2] X. L. Mao, X. F. Song, G. M. Lu, Y. Z. Sun, Y. X. Xu, and J. G. Yu, "Effects of metal ions on crystal morphology and size of calcium sulfate whiskers in aqueous $\mathrm{HCl}$ solutions," Ind. Eng. Chem. Res., vol. 53, pp. 17625-17635, 2014.

[3] L. C. Deng, Y. F. Zhang, F. F. Chen, S. T. Cao, S.W. You, Y. Liu, and Y. Zhang, "Reactive crystallization of calcium sulfate dihydrate from acidic wastewater and lime," Chin. J. Chem. Eng., vol. 92, pp. 1303-1312, November 2013.

[4] X. F. Song, L. N. Zhang, J. C. Zhao, Y. X. Xu, Z. Sun, P. Li, and J. G. $\mathrm{Yu}$, "Preparation of calcium sulfate whiskers using waste calcium chloride by reactive crystallization,” Cryst. Res. Technol., vol. 46, pp. 166-172, February 2011.

[5] X. Y. Song, S. X. Sun, W. L. Fan, and H. Y. Yu, "Preparation of different morphologies of calcium sulfate in organic media," J. Mater. Chem., vol. 13, pp. 1817-1821, May 2003.

[6] A. Y. Xu, H. P. Li, K. B. Luo, and L. Xiang, "Formation of calcium sulfate whiskers from $\mathrm{CaCO}_{3}$-bearing desulfurization gypsum,” Res. Chem. Intermed., vol. 37, pp. 449-455, February 2011.

[7] S. Abidi, B. Nait-Ali, Y. Joliff, and C. Favotto, "Impact of perlite, vermiculite and cement on the thermal conductivity of a plaster composite material: experimental and numerical approaches,” Compos. Pt. B-Eng., vol. 92, pp. 28-36, May 2016.

[8] J. C. Rubio-Avalosa, A. Manzano-Ramírezb, J. M. Yañez-Limónb, M. E. Contreras-Garcíac, E. M. Alonso-Guzmánd, and J. González-Hernández, "Development and characterization of an inorganic foam obtained by using sodium bicarbonate as a gas generator," Constr. Build. Mater, vol. 19, pp. 543-549, September 2005.

[9] P. Chindaprasirt, K. Boonserm, T. Chairuangsri, W. Vichit-Vadakan, T. Eaimsin, T. Sato, and K. Pimraksa, "Plaster materials from waste calcium sulfate containing chemicals, organic fibers and inorganic additives," Constr. Build. Mater., vol. 25, pp. 3193-3203, August 2011.

[10] S. Abidi, B. Nait-Ali, Y. Joliff, and C. Favotto, "Impact of perlite, vermiculite and cement on the thermal conductivity of a plaster composite material: experimental and numerical approaches," Compos. Pt. B-Eng., vol. 68, pp. 392-400, January 2015.

[11] J. R. McGraw Jr. and F. W. Mowrer, "Flammability and dehydration of painted gypsum wallboard subjected to free heat fluxes," Fire Safety Sci., vol. 5, pp. 1003-1014, January 2000.

[12] D. I. Kolaitis, E. K. Asimakopoulou, and M. A. Founti, "Fire protection of light and massive timber elements using gymsum platerboards and wood based panels: A large-scale compartment fire test,” Constr. Build. Mater., vol. 73, pp. 163-170, December 2014.

[13] S. Grandjean, J. Absi, and D. S. Smith, "Numerical calculation of the thermal conductivity of porous ceramics based on micrographs," J. Eur. Ceram. Soc., vol. 92, pp. 2669-2676, July 2006.

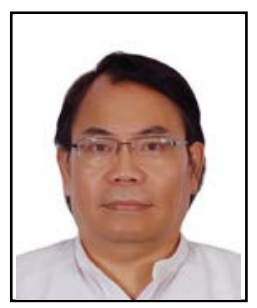

Hsi-Chi Yang was born in Taichung, Taiwan on April 5, 1953. He received his B.S. degree in architecture from Chung Yuan College of Science and Engineering, Chungli, Taiwan, in 1976, M.A. degree in architecture, M.S. degree in building construction and $\mathrm{PhD}$ degree in civil engineering from University of Florida, USA, in 1980, 1982 and 1988, respectively.

He joined the Department of Construction Management in Chung Hua University, Hsinchu, Taiwan from 1997 to present. He is currently an associate professor and was the departmental head from Aug. 2011 to Jan. 2015. He is a registered professional engineer in Texas, USA, and a registered structural engineer in Taiwan. He has practiced structural engineering consulting for more than ten years and designed more than 300 earthquake resisting structures. His research is in the areas of nonlinear finite element analysis, construction management, construction materials, green architecture and building information modeling. His current researches include lightweight concrete and eco-environmental coating materials.

Dr. Yang is a member of the following professional societies: American Society of Civil Engineers, American Concrete Institute, Taipei Structure Engineering Association, Taiwan Structural Engineers Association, Taiwan Society of Construction Engineers and American Project Management Association. He is also one of the managing directors in Taiwan Society of Construction Engineer and American Project Management Association. 